\title{
Implementing Elements of The Physics Suite at a Large Metropolitan Research University
}

\author{
Costas Efthimiou $^{1}$, Dan Maronde ${ }^{1}$, Tim McGreevy ${ }^{2 *}$, Enrique del Barco ${ }^{1}$, Stefanie McCole $^{3 \dagger}$ \\ ${ }^{1}$ Department of Physics, University of Central Florida, Orlando, FL. \\ ${ }^{2}$ Department of Physics, Embry-Riddle Aeronautical University, Daytona Beach, FL. and \\ ${ }^{3}$ Department of Physics, Old Dominion University, Norfolk, VA.
}

\begin{abstract}
A key question in physics education is the effectiveness of the teaching methods. A curriculum that has been investigated at the University of Central Florida (UCF) over the last two years is the use of particular elements of The Physics Suite. Select sections of the introductory physics classes at UCF have made use of Interactive Lecture Demonstrations as part of the lecture component of the class. The lab component of the class has implemented the RealTime Physics curriculum, again in select sections. The remaining sections have continued with the teaching methods traditionally used. Using pre- and post-semester concept inventory tests, a student survey, student interviews, and a standard for successful completion of the course, the preliminary data indicates improved student learning.
\end{abstract}

\section{INTRODUCTION}

The University of Central Florida (UCF) is a large metropolitan university located in Orlando, Florida. Shortly before this study was started, the U.S. Department of Education National Center for Education Statistics ranked UCF as the sixth largest university in the country based on a Fall 2006 enrollment of 46,646 students [1]. Since that time, the university's enrollment has grown to over 55,000, making UCF the third largest university in the United States going into the Fall 2009 semester 2, 3]. The calculus-based introductory physics courses, Physics I (Newtonian Mechanics) and Physics II (Electricity and Magnetism with some Optics) are required for all students of the College of Engineering and Computer Science. This college alone had an enrollment of over 6000 in the spring of 2009 [4]. The large number of students going through the introductory classes each semester, along with the students from the College of Sciences, which includes the Physics Department, and a large contingent of students from other colleges taking the department's physical science class make UCF's Physics Department the second-largest in the country based on the number of credit-hours taught per semester [5]. The teaching of these introductory classes is a large-scale operation, with ten to twelve lecture sections of eighty to over one-hundred students taught each semester, along with twenty to twenty-two lab sections of thirty to thirty-five students each. Retention of the students within the majors that make up the science, technology, engineering and mathematics fields (STEM) is a challenge for UCF as well as universities nationally [6]. The introductory physics courses are one of the first large hurdles that students must clear on their

[*] Prior to August 2008:Department of Physics, University of Central Florida, Orlando, FL.

[†] Prior to August 2009:Department of Physics, McDaniel College, Westminster, MD. way to a STEM degree.

There are many innovative approaches to teaching introductory physics (see Ref. [7] and references therein). One that has been demonstrated to effectively improve students' conceptual learning is curriculum presented in The Physics Suite [7, 8]. Some elements of The Physics Suite apply readily to the large-scale approach to the teaching of the introductory classes at UCF, with little or no change to the scheduling format or the infrastructure used by the department. Interactive Lecture Demonstrations (ILD) [9] can be used effectively in a large lecture hall setting, so they can be implemented in any of the sections scheduled at UCF. Similarly, RealTime Physics (RTP) [11 13] is designed for use in a lab setting with groups of two to four students performing experiments using computers and probeware, much of which is already used in the UCF introductory physics labs. These elements of The Physics Suite bring physics education research-based curriculum into an existing largescale physics instruction program while maintaining the department's existing method of scheduling and class structure and making use of the department's existing equipment.

The evaluations outlined in this paper provide evidence of improved student learning due to the effectiveness of including The Physics Suite methods as a major part of the instruction in the introductory physics classes. The large scale of UCF's introductory physics program has allowed a comparison of conceptual learning between significant numbers of students taking part in the new method of instruction with those in traditional instruction, as well as those with partial involvement in both methods, over a short span of time. The number of sections of each class available for this survey has also provided the opportunity to study the relative benefits of $I n$ teractive Lecture Demonstrations and RealTime Physics when implemented seperately as well as in concert. 


\section{INTRODUCTORY PHYSICS CLASSES AT UCF, AND CHANGES MADE TO IMPLEMENT THE PHYSICS SUITE}

The lecture sections of the introductory physics classes at UCF are taught in an auditorium-style lecture hall seating 80-120 students. Traditional format lectures are taught in a visual method determined by the instructor - that is, either projected powerpoint slides or flashing of transparencies or blackboard/whiteboard presentation. A few instructors have made occasional use of electronic student response systems (ERS) to incorporate some active student participation into the format and/or have used a combination of the visual methods for the delivery of the lectures.

The sections chosen for participation in The Physics Suite project used Interactive Lecture Demonstrations during one lecture class each week. A demonstration relating to the current topic being addressed in the class is set up. Students are asked to make a prediction of what results will be seen during the demonstration. The predictions are recorded as a poll, using the ERS. Students are then encouraged to interact in small groups, discussing their predictions and explaining their reasoning. After the discussion interval, students are polled again and the results are displayed. The demonstration is then conducted and students can see the actual results. Finally, the physical principles involved are discussed, with participation both from students who had reasoned correctly and from some who had based their answers on incorrect preconceptions. This approach of direct confrontation of preconceptions with actual demonstrations, requiring the students to thoroughly reason through the problem both before and after the demonstration has been shown to be an effective teaching method. It develops deeper understanding by connecting students' intuition to the concepts addressed, and it is effective in changing flawed preconceptions [14, 15, 17, 18].

The lab component of the introductory classes is a separate, one credit-hour class. The classrooms are arranged for eight stations of four students each, and each station equipped with a computer and Pasco CI-6560 interface. The experiments used in the traditional format lab are mostly "cookbook"-style. The students present their results in a report composed outside of class and turned in the following meeting. The format of the report is determined by the instructor. Part of the focus of the manual is on experimental set-up and method, and there is some introduction to error analysis.

The lab sections using RealTime Physics as their lab manual are set in the same rooms and make use of much of the same equipment as the traditional format labs. The RTP manual makes use of a guided-inquiry approach to the execution of the experiments. After a brief outline of the experimental set-up, the students are asked to make predictions of the results they expect to see. Like the ILDs in the lecture sections, this prediction step will target preconceptions and lead to discussion of the underlying principles among members of the lab group. For most activities, the data is plotted in real time, as the experiment takes place. The students are encouraged to make multiple runs of each experiment, watching the relation between the physical activity and the mathematical plot. The actual results are compared with the predictions made earlier. Questions are asked to get the students to think about the physical principles determining the experimental results. Some mathematical analysis is done with the graphs and data from the experiment to show relations between physical quantities.

An example of an activity performed during one of the one-dimensional motion labs from Physics I follows: A student holds a ball above a motion detector that is hooked to a computer. The students in the group predict what will happen to velocity and acceleration for the ascent, turning point, and descent of the ball thrown vertically. Then the ball is thrown in the air so the motion detector can plot velocity versus time and acceleration versus time. Now students discuss the results and can see that even though velocity changes, acceleration is constant. The plots of velocity and acceleration are compared, illustrating the mathematical relation between the quantities. Careful attention to the graphs also helps illustrate the vector nature of the quantities [21 23].

The lab report is completed within the lab class time, consisting of answering the questions posed during the activities. There is a set of homework questions following each lab, designed to reinforce concepts developed through the activities in the lab. Through the Fall 2007 semester, the first semester of the project, the homework was optional. Since then, the students have been required to turn this in at the start of the following lab. The emphasis of the RTP labs is on understanding the physical concepts addressed and interpreting the graphs of mathematical relations followed by the physical quantities [19, 20].

\section{METHOD OF EVALUATION}

To evaluate the effectiveness of these portions of The Physics Suite method at UCF, all the students in the introductory physics classes were given a pre-test during the first meeting of the lab section, and a post-test on the last day of the lab. The tests used are concept inventory-style tests and the same tests were given to all students both times. The Physics I test is the Force and Motion Concept Evaluation and is included as an appendix to the Thornton/Sokoloff article cited [10]. The Physics II test is the Electric Circuits Concept Evaluation, also created by Sokoloff and Thornton. The difference between each student's score between the preand post-tests was not the score evaluated. Instead, students' pre- and post-test scores were compared based on the percentage of material that they learned during the semester. The improvement score, normalized gain as introduced by Hake, calculates what percentage of the 
questions missed on the pre-test are answered correctly on the post-test. The formula used to calculate the normalized gain is Gain $=\frac{(\text { Post Correct })-(\text { Pre Correct })}{(\text { Perfect Score })-(\text { Pre Correct })} \times 100$. [16]

The students in each semester registered for their lecture and lab classes without knowing if either would include a component of The Physics Suite, so their placement was random. A small number of students each semester take either the lab or lecture component alone. The students taking only the lecture component did not take the concept evaluation tests.

The scores from the pre- and post-tests were grouped into four categories: students taking an ILD lecture section and an RTP lab, students taking an ILD lecture section and a traditional format ( $\mathrm{TF}$ ) lab, students taking a traditional format (TF) lecture and an RTP lab, students taking a TF lecture and a TF lab. Students who missed either test due to add/drop of a class or an absence on either test day were not counted. Also, for any student who had taken a pre-test and switched sections and took it again the lower score was kept. These statistics were used to evaluate the effect of The Physics Suite elements on conceptual learning.

The students' successful completion of the course, defined as attaining a "C" or better, is compared among the four categories. The percentage of each category that successfully completed the course during the study is presented for both Physics I and Physics II.

Finally, student opinions were solicited. Interviews were conducted with student volunteers after two semesters, the Spring 2008 semester and the Spring 2009 semester. The students did not receive any monetary or grade compensation for the interviews. In the spring of 2008, twenty-eight students were interviewed, eight students from Physics I and twenty from Physics II. Six of the students were Physics II RTP students who had taken Physics I during the fall with the RTP method. A survey was given to all sections of the lab classes at the end of the Spring 2009 semester. Excerpts from the interviews and results from the survey are presented.

\section{EVALUATION: CONCEPT TEST RESULTS}

The students' conceptual learning as measured by the performance on the Force and Motion Concept Evaluation(FMCE) and Electric Circuits Concept Evaluation (ECCE) pre- and post-tests is presented first. The comparison is made between students taking sections using either Interactive Lecture Demonstrations(ILD) in their lecture, RealTime Physics(RTP) in their lab, or both components of The Physics Suite(ILD \& RTP) and those taking only traditional format classes $(\mathrm{TF})$ in both their lecture and lab component.

Figures 1 and 2 show the two-year cumulative performance in Physics I (PHY2048) and Physics II (PHY2049) separately. The gains for all formats are higher in Physics I, with students taking both ILD and RTP components

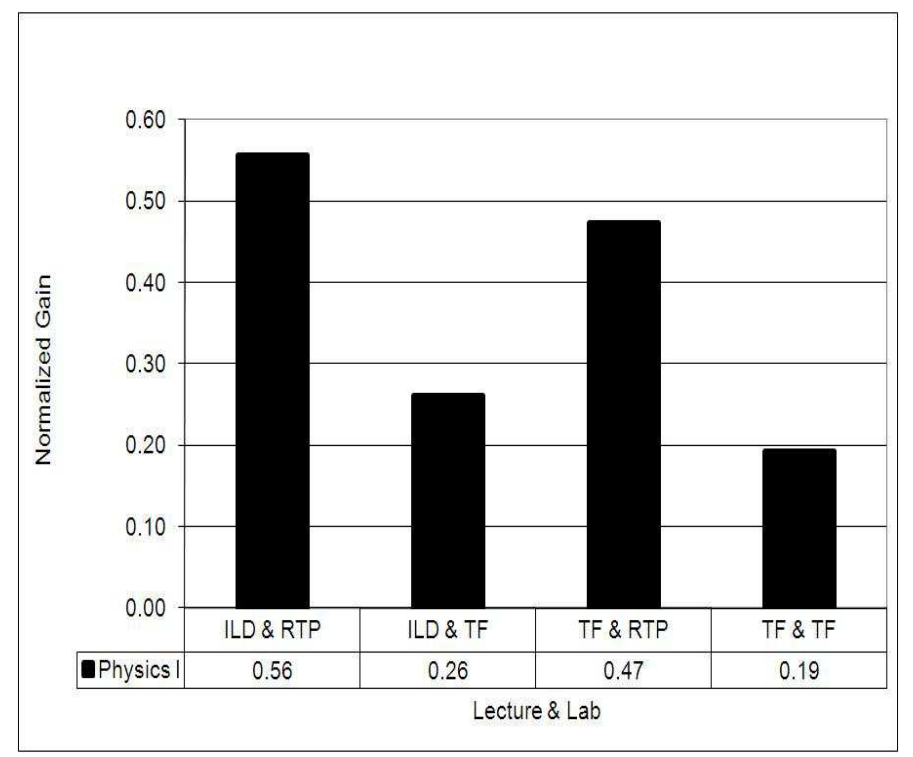

FIG. 1: Cumulative Physics I results

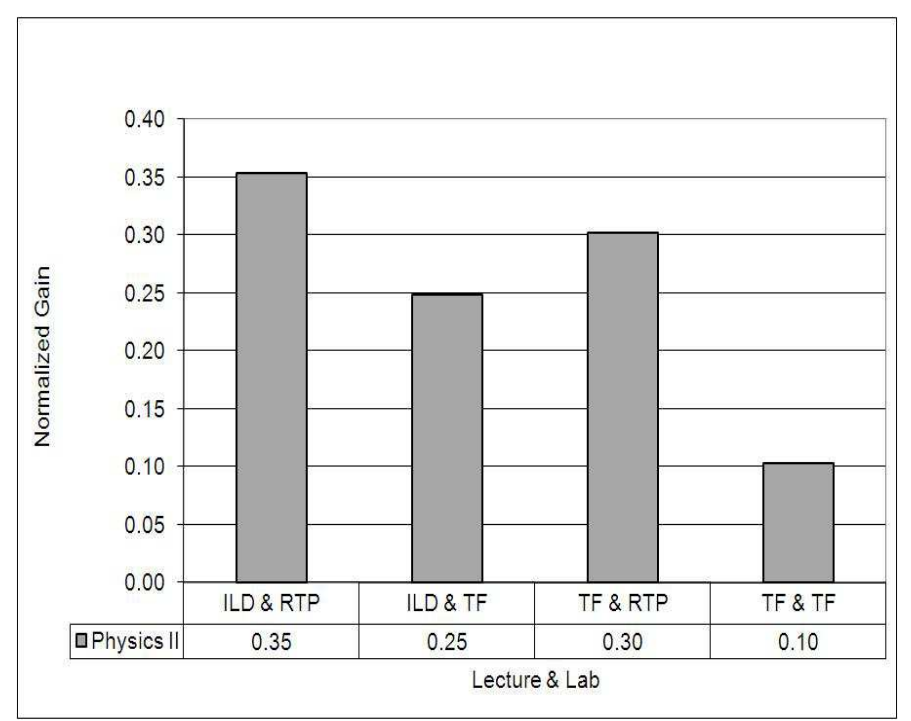

FIG. 2: Cumulative Physics II results

gaining over $50 \%$ compared to $19 \%$ for students having both components in the traditional format. In Physics II, the gains are less for all formats, but students taking any component of The Physics Suite more than doubled their gain over the TF-only group.

The remaining figures for this section show the performance of students in the introductory classes by semester for the first two years of the project, from the most recent results back to the start of project. Note that in PHY2049 there are no students in the TF lab categories after the first semester of implementation. After positive results in the initial semester of the project, all sections of the Physics II lab component were switched to the RTP format.

The latest results from the Spring semester of 2009 are 


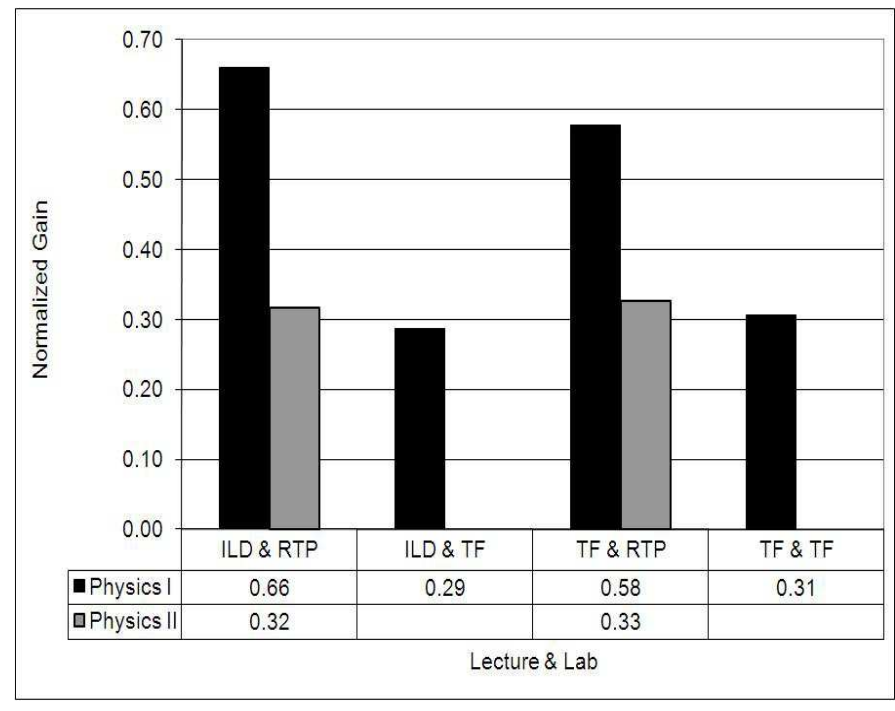

FIG. 3: FMCE \& EECE results for Physics I \& II from Spring 2009

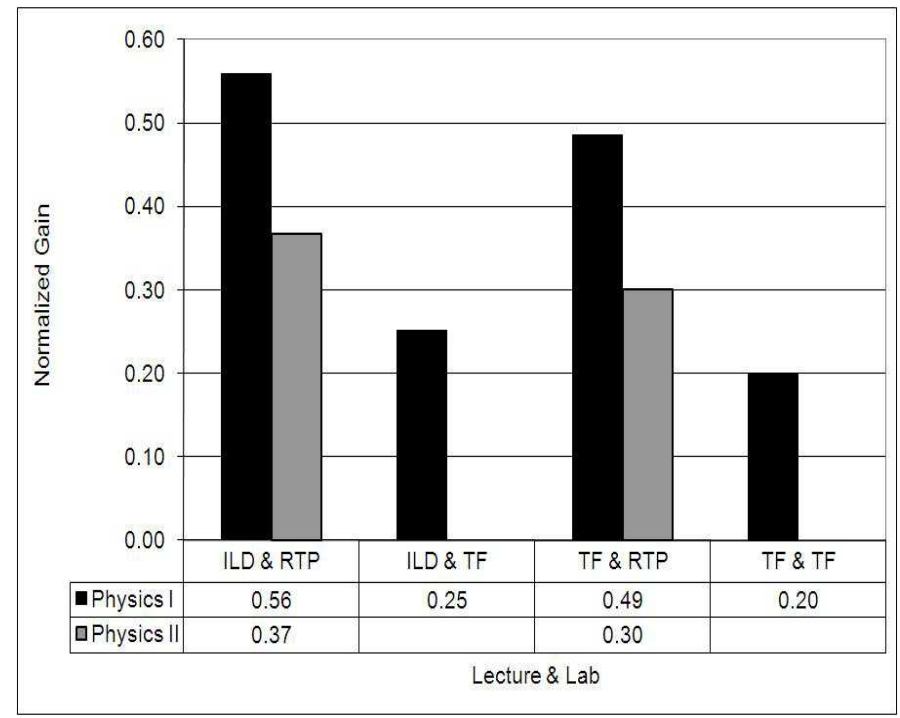

FIG. 4: FMCE \& EECE results for Physics I \& II from Fall 2008

shown in Figure 3. Figure 4 shows the results from the Fall semester of 2008. Figure [5] shows the performance in the Spring of 2008. Finally, Figure 6 shows the Fall of 2007, the first semester of implementation.

For Physics I, the number of students in each category and for each semester is given in Table I. The Physics II numbers are in Table II]. Fall 2007 was the only semester with traditional format labs in Physics II.

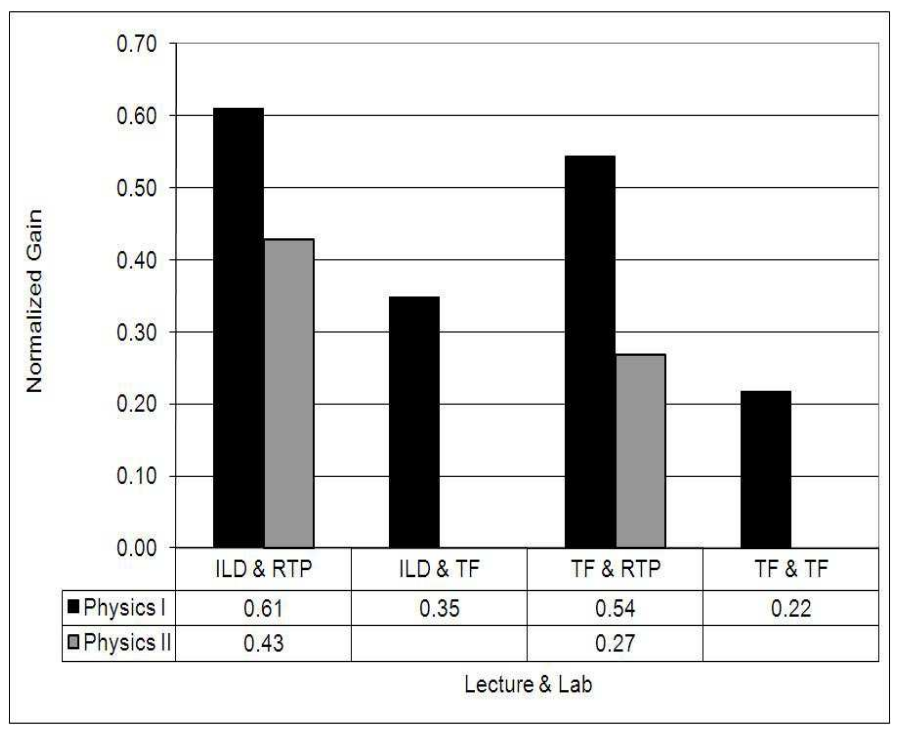

FIG. 5: FMCE \& EECE results for Physics I \& II from Spring 2008

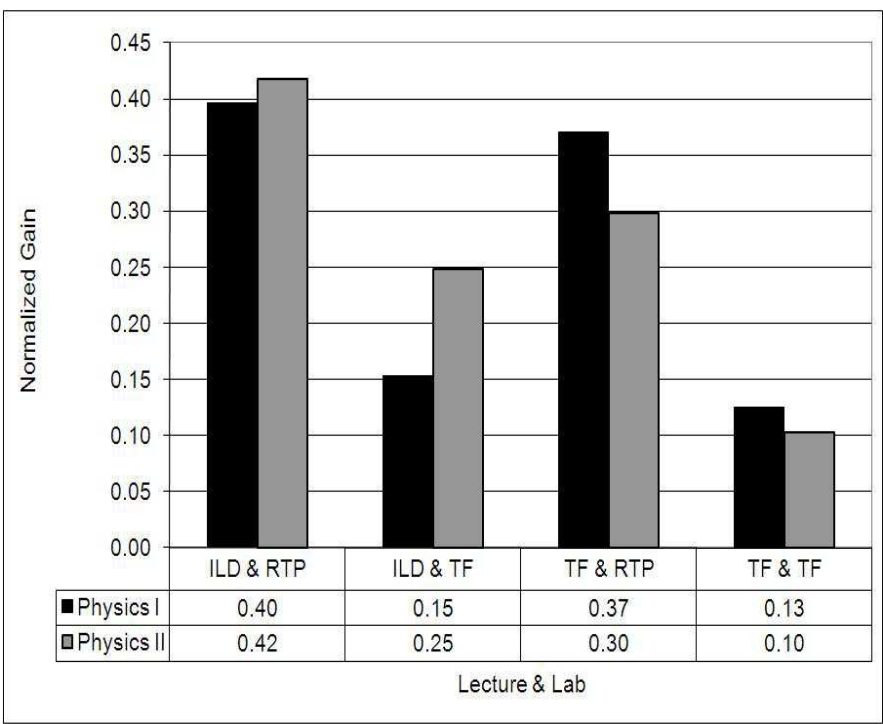

FIG. 6: FMCE \& EECE results for Physics I \& II from Fall 2007. This was the only semester to include TF labs in Physics II.

Physics I Numbers by Semester

\begin{tabular}{lcccc} 
Semester & ILD\&RTP & ILD\&TF & TF\&RTP & TF\&TF \\
\hline Fall 2007 & 26 & 57 & 72 & 270 \\
Spring 2008 & 15 & 42 & 43 & 186 \\
Fall 2008 & 19 & 49 & 60 & 104 \\
Spring 2009 & 32 & 121 & 34 & 120 \\
\hline Total & 92 & 269 & 209 & 680
\end{tabular}

TABLE I: The number of students taking the FMCE, by semester. 
Physics II Numbers by Semester

\begin{tabular}{lcccc} 
Semester & ILD\&RTP & ILD\&TF & TF\&RTP & TF\&TF \\
\hline Fall 2007 & 17 & 21 & 66 & 191 \\
Spring 2008 & 15 & & 141 & \\
Fall 2008 & 46 & & 210 & \\
Spring 2009 & 78 & & 210 & \\
\hline Total & 156 & 21 & 627 & 191
\end{tabular}

TABLE II: The number of students taking the EECE, by semester.

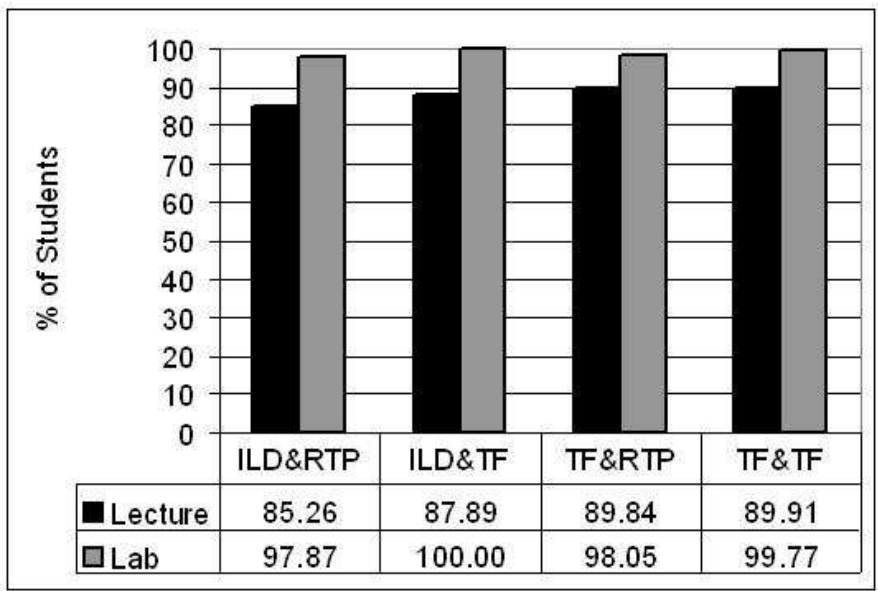

FIG. 7: Percentage of students successfully completing the introductory physics classes (Fall 2007-Spring 2009)

\section{EVALUATION: SUCCESSFUL CLASS COMPLETION}

The FMCE and ECCE test conceptual understanding. Another important measure of the success of a course is given by the percentage of students that successfully complete the course. In the case of the introductory physics courses, the majority of the students are from the College of Engineering and Computer Science, which requires a C or better in the core courses. Figure 7 shows the percentage of students attaining at least a $\mathrm{C}$ grade in Physics I from the Fall 2007 semester through the Spring 2009 semester. Again, the performance is divided into the categories based on the combination of lecture and lab instruction method. This is the one area where taking both ILD and RTP components has not shown to be an advantage. The effect may be masked by less grade inflation in the ILD classes taught by the project's PI(C.E.), and by the stricter rules of student evaluation he has established in the RTP labs. Since the combination of the two elements of The Physics Suite created the largest gain measured in conceptual understanding, it may be that it leads to a bigger split between the successful students and those that are still struggling. This may lead to

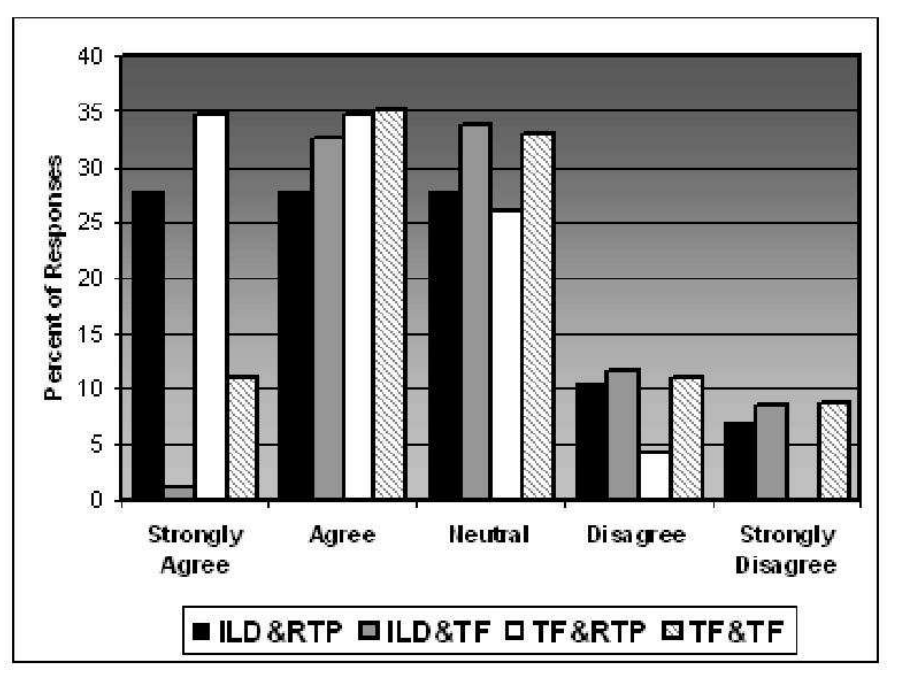

FIG. 8: Percentage of student responses to the statement: "The experiments performed in the lab have caused me to change my mind about how some physical process works."

a higher withdrawal rate. At this point the investigation has not differentiated between withdrawals and failures. The retention issue is an important one and the other apparent successes of the project make it seem that it should help with this also.

\section{EVALUATION: STUDENT INPUT}

The evaluation also involved student input. A survey was given to all students taking the post-test at the end of the Spring 2009 semester. The survey consisted of fifteen statements relating to the benefits of the lab component of the course, the correlation between the lab and lecture components, the recitation sessions conducted during the lab meeting time, and possible ways to maximize the benefit of the lab component. Students were asked to rank their agreement with each statement on a five-point scale: strongly agree, agree, neutral, disagree, or strongly disagree.

Here the responses of Physics I students are shown for two statements that are key to both the motivation for, and the success of the implementation of The Physics Suite. They refer to the goal of challenging common preconceptions held by students of the introductory physics classes, which The Physics Suite curriculum is written specifically to address, and the goal of better coordinating the lab component topics with the lecture component topics chronologically during the semester.

Figure 8 shows the responses to the statement, "The experiments performed in the lab have caused me to change my mind about how some physical process works." The students who had taken a RealTime Physics lab (RTP) had a higher percentage of positive responses than those taking the traditional format lab (TF). The strongest positive response came from students taking 


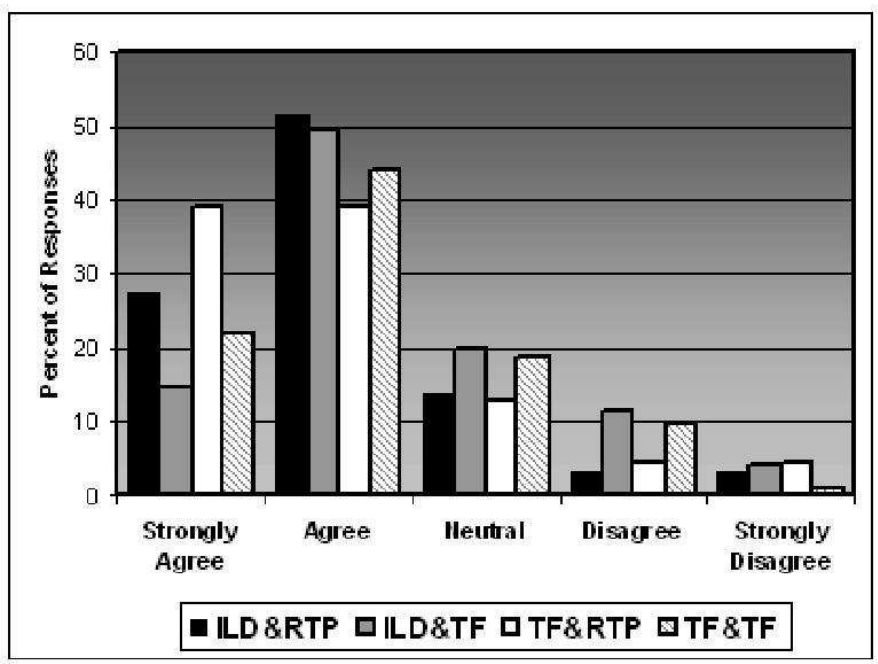

FIG. 9: percentage of student responses to the statement: "There is a connection between the concepts addressed by the lab experiments and the theory covered in the lecture class."

the RTP lab, with the traditional lecture component. These students seemed to have a strong sense that the lab exercises contributed to their understanding of the physical principles involved. The responses of the students taking an RTP lab component with an ILD lecture, although still positive, were not as strong as the RTP lab with traditional lecture students. This is the group that performed the highest on both the conceptual test and in the lecture component grade. The lower positive response may be due to the wording of the statement. These students may feel that their preconceptions were challenged during the ILD lecture as well as during the RTP lab experiments.

Figure 9 shows the percentage of the responses to the statement, "There is a connection between the concepts addressed by the lab experiments and the theory covered in the lecture class." Again, students have responded more positively if they had the RTP lab than if they had a TF lab.

Student volunteers were interviewed following both the Spring 2008 and Spring 2009 semesters. The earlier interviews have been transcribed and the student feedback is summarized here.

On major items, such as 'Do you like the format?', 'Have the experiments changed misconceptions?', and 'Do the experiments help you learn physics?', the majority of students gave positive feedback. The interactive nature of the RTP labs was praised by a number of students. Many students claimed to have had preconceptions modified by conducting the experiments in the RTP lab. A question in the interview addressed the homework and most students had a positive response. It was an indication the homework was fulfilling its intended purpose. The interviews were conducted in a focus group setting. Examples of two questions and typical student responses follow. The responses have been paraphrased to accommodate grouping of like responses.

1. Do you like this (overall) format as compared to a traditional lab format where you take all the data and later write a report? Why?

- Much more interactive

- More effective because you forget when you try and write the report at home

- Somewhat, explains to a point that makes you find out a purpose

- Good to answer questions as going through

- Does more to reinforce

2. Do the lab report questions help understand the material?

- Helps understand

- Makes you stop and think

- Helps if you take your time to do it

- Observing then writing reinforces

- Seeing the result really helps with concept

\section{IMPLEMENTATION ISSUES}

Although the students are encouraged to do their best on the pre- and post-tests, and most do, there are some who just quickly mark down an answer. There needs to be an incentive for all to try their best. It cannot be directly related to their grade because, in the case of the pre-test, it would be unfair to grade students on material they have not seen. The graduate teaching assistants have been asked to offer some form of extra credit to students as an incentive to give a full effort on both tests. Some methods that have been tried are rewarding the top-scoring students on the pre-test, rewarding both the top scoring and highest normalized gain students on the post-test, and counting the post-test as a full-score replacement quiz grade based on effort (as judged by the instructor).

Another issue is that as time goes on students from the past RTP labs will have corrected homework that they can share with current RTP students. Although this would not show directly in the pre/post test results, some students may not put full effort into learning. A possibility may be to have different homework sets appended to those in the lab manual.

Attaining a good correlation between the lab and the current topic being covered in the lecture component is always a challenge and was part of the motivation for undertaking the project. Much of the problem involves the different pace of the various lecture instructors. The RTP labs for Physics I have been in fairly good agreement with the lectures. Physics II has been more difficult. The labs start immediately with circuits, while the 
lecture deals with static charges, electric force and electric fields. There is also a point where the lecture starts addressing magnetism and there are no corresponding labs. The geometric optics labs have been inserted into the lab curriculum at this point, and then circuits are resumed once the lecture begins with some introduction of induction. Although students have had some complaints about the disconnect between the two components, most have been glad for the experience with circuits when that topic is reached in lecture.

\section{CONCLUSION}

There is strong evidence, based on the results from the pre- to post-test gains on the FMCE and ECCE, that The Physics Suite elements implemented into the introductory physics classes at UCF have a positive effect on students' conceptual learning. This is especially true when both the Interactive Lecture Demonstrations and RealTime Physics labs are used in conjunction. However, the investigation shows evidence that either component benefits student learning when used alone. This makes The Physics Suite a good option for a large-scale physics program with many different instructors. RealTime Physics as a stand-alone method for lab instruction pairs well with the lecture component of the course, whether or not the lecture instructor chooses to include Interactive Lecture Demonstrations as part of the course.

This improved performance does not seem to have affected the number of students who successfully complete the courses, although those that do succeed are doing so at a higher level. The students that withdraw or fail often do not attend class, or do not put any effort into their studies of the subject. Even if the presentation of the material is improved, it does not have an effect on this group. The effort to stimulate learning in the lowest performing students is an area that will require further focus.

There is also evidence that the students themselves feel that the approach of The Physics Suite has positively impacted their learning. Responses to the survey questions and statements made during the interviews indicate a perception among the students that the inquiry-based activities of RealTime Physics and the active participation in lecture required in Interactive Lecture Demonstrations play a large role in helping them grasp the difficult material of the introductory physics classes.

The success of the project through the first two years, based on the evaluations done and also on positive feedback from the students themselves indicates that there is good reason to continue with, and expand, the implementation of The Physics Suite at The University of Central Florida.

\section{ACKNOWLEDGMENTS}

The authors would like to extend thanks for the help provided by Professors David Sokoloff, Ronald Thornton and Priscilla Laws, who have been the consultants in the implementation of the The Physics Suite at UCF, and Professor Ken Krane, who has been the evaluator. The lab manuals and concept inventory tests used for Physics I and II have been created by David Sokoloff, Ronald Thornton and Priscilla Laws. 9, 11 13.

This work was supported by the Department of Undergraduate Education in the National Science Foundation under Grant No. DUE 0633157. S. McCole was supported by an REU grant of the National Science foundation (DMS 0649159).

Any opinions, findings, and conclusions or recommendations expressed in this material are those of the author(s) and do not necessarily reflect the views of the National Science Foundation.
[1] U.S. Department of Education National Center for Education Statistics, http://nces.ed.gov/fastfacts/

[2] WFTV, Orlando, FL, http://www.wftv.com/education/

[3] University of Central Florida, UCF Today, http://today.ucf.edu/ucf-moves-up-now-nations-3rd-largest/

[4] University of Central Florida College of Engineering and Computer Science, http://www.cecs.ucf.edu/about/

[5] American Institute of Physics, AIP Pub. No. R-394.14, http://www.aip.org/statistics/

[6] National Science Foundation, http://www.nsf.gov/news/

[7] E. F. Redish, Teaching Physics with the Physics Suite, Wiley 2003.

[8] Karen Cummings, Priscilla Laws, Edward F. Redish, Patrick Cooney, David Sokoloff, Ronald Thornton, The Physics Suite, John Wiley and Sons, Inc. 2004.

[9] David Sokoloff, Ronald Thornton. Interactive Lecture Demonstrations, Active Learning in Introductory Physics, John Wiley and Sons, Inc. 2006.

[10] Ronald Thornton, David Sokoloff. Assessing Student
Learning of Newton's Laws: The Force and Motion Conceptual Evaluation and the Evaluation of Active Learning Laboratory and Lecture Curricula, Am. J. Phys. 66(4). April 1998.

[11] David Sokoloff, Ronald Thornton, Priscilla Laws. Real Time Physics Active Learning Laboratories: Module 1 Mechanics, John Wiley and Sons, Inc. 2004.

[12] David Sokoloff, Ronald Thornton, Priscilla Laws. Real Time Physics Active Learning Laboratories: Module 3 Electric Circuits, John Wiley and Sons, Inc. 2004.

[13] David Sokoloff, Ronald Thornton, Priscilla Laws. Real Time Physics Active Learning Laboratories: Module 4 Light and Optics, John Wiley and Sons, Inc. 2004.

[14] J. Clement, D. Brown, A. Zeitsman, Not all preconceptions are misconceptions: Finding "anchoring conceptions" for grounding instruction on students' intuition, Int. J. Sci. Educ. 11 (spec. issue), 554-565 (1989).

[15] R. R. Hake, Socratic pedagogy in the introductory physics laboratory, Phys. Teach. 33, 1-7 (1992). 
[16] R. R. Hake, Interactive engagement versus traditional methods: A six-thousand student survey of mechanics test data for introductory physics courses, Am. J. Phys. 66(1). January 1998.

[17] L. C. McDermott, P. S. Shaffer, Research as a guide for curriculum development: An example from introductory electricity. Part I. Investigation of student understanding, Am. J. Phys. 60, 994-1003 (1992); erratum, 61, 81 (1993).

[18] David Sokoloff, Ronald Thornton, Using interactive lecture demonstrations to create an active learning environment, Phys. Teach. 35, 340-347 (1997).

[19] David Sokoloff, Ronald Thornton, Learning motion concepts using real-time microcomputer-based laboratory tools, Am. J. Phys. 58, 858-867 (1990).

[20] E. F. Redish, J. M. Saul, R. N. Steinberg, On the effectiveness of active-engagement microcomputer-based laboratories, Am. J. Phys. 65, 45-54 (1997).

[21] L. C. McDermott, M. L. Rosenquist, E. H. van Zee, Student difficulties in connecting graphs and physics: Examples from kinematics, Am. J. Phys. 55, 503-513 (1987).

[22] F. M. Goldberg, J. H. Anderson, Student difficulties with graphical representations of negative values of velocity, Phys. Teach. 27, 254- 260 (1989).

[23] R. J. Beichner, Testing student interpretation of kinematics graphs, Am. J. Phys. 62, 750-762 (1994). 